\title{
PUNCH FORCE BEHAVIOR DURING MICRO V-BENDING PROCESS OF THE COPPER FOIL
}

\author{
Gandjar Kiswanto $^{1 *}$, Aida Mahmudah ${ }^{1,2}$, Dedi Priadi ${ }^{3}$ \\ ${ }^{1}$ Department of Mechanical Engineering, Faculty of Engineering, Universitas Indonesia, Kampus UI \\ Depok, Depok 16424, Indonesia \\ ${ }^{2}$ Manufacturing Design Engineering Department, Politeknik Manufaktur Bandung, Bandung 40135, \\ Indonesia \\ ${ }^{3}$ Department of Metallurgy and Material Engineering, Faculty of Engineering, Universitas \\ Indonesia, Kampus UI Depok, Depok 16424, Indonesia
}

(Received: June 2017 / Revised: July 2017 / Accepted: October 2017)

\begin{abstract}
Sheet metal bending is defined as a straining process of flat strip material around a linear axis. The micro V-bending process was conducted to investigate its punch force behavior with 0.1 $\mathrm{mm}$ thick copper foil. The $\mathrm{V}$-shaped configuration of the punch and die provides a simplicity of tools and an ability to produce different bending angles with a single tool. During the straining of material, a unique force profile, which is related to punch trajectory, occurs. The process was performed with the punch speeds $0.5 \mathrm{~mm} / \mathrm{s}, 1.0 \mathrm{~mm} / \mathrm{s}, 5.0 \mathrm{~mm} / \mathrm{s}$ and $10.0 \mathrm{~mm} / \mathrm{s}$. The results showed that the punch force profile consists of the free-bending stage and the coin-bending stage. In the free-bending stage, the force magnitude was not influenced by the punch speed for the same geometrical and mechanical properties of the sheet material. Furthermore, during the coin-bending stage, the force magnitude increased significantly since the material needed to be bottomed.
\end{abstract}

Keywords: Copper foil; Micro V-bending process; Punch force behavior; Punch speed

\section{INTRODUCTION}

The increasing demand for micro-components, due to the miniaturization trend, has prompted many researchers to develop a micro-manufacturing system and investigate the process at a micro level. Micro sheet metal forming is one of the most popular fields to be observed since it has been widely applied in producing micro-parts. Micro-bending is one of the basic forming processes that produce a micro-component with 3D contours, such as contacts/switches for micro-electrics , mechanical sensors, and housing for optical devices (Kiswanto et al., 2017). In sheet metal manufacturing technology, bending is defined as a straining process of flat strip material around a linear axis (Qin, 2010). During the straining process, one of the surfaces of the material may be stretched while the other is compressed. Similar to the macro level, several basic techniques in bending process can be used to produce a bent-shape at the micro level; these include U-bending, V-bending, and wiping-bending. For a single bending process, Vbending is more popular because of the simplicity of the tool and process involved. Chen and Jiang (2011) have been conducted the micro V-bending experiment, and discovered that maximum punch force and yield strength decreased with $\mathrm{t} / \mathrm{d}$ ratio reduction.

\footnotetext{
*Corresponding author's email: gandjar_kiswanto@eng.ui.ac.id, Tel. +62-21-7270032, Fax. +62-21-7270033 Permalink/DOI: https:// doi.org/10.14716/ijtech.v8i7.747
} 
Vollertsen et al. (2004) characterized punch force and friction force in the micro deep drawing process and declared that the friction coefficients on the flange and the die radius were not equal since the normal pressures were different.

Due to the punch force has a close relationship with the friction force, the tool lubrication is required. The DLC (diamond-like carbon) film, one of the lubricants, was found to decrease the drawing force and to increase the LDR (limit drawing ratio) of the material (Gong et al., 2011; $\mathrm{Hu}$ et al., 2012). Otherwise, Zheng et al. (2013) observed the forming load required to perform modeling, and also analyzed the dry friction in micro-forming. It was found that non-contact surface grains had a strong influence to the forming load and friction coefficient.

Previous studies about forming load characterization have focused on the average forming load in order to investigate the tribological size effect. In this paper, the investigation of the micro $\mathrm{V}$ bending process was conducted to study the punch force behavior with some punch feed variation. Pure copper with $0.1 \mathrm{~mm}$ thickness was selected as the bending specimen.

\section{MICRO V-BENDING PROCESS}

The V-bending process consists of two common methods, namely, free-bending (also known as air-bending) and coin-bending (Boljanovic, 2004). By controlling the punch trajectory, various bending angles can be obtained through the application of free-bending. On the other hand, the coin-bending method provides only one specific angle using a single V-bending tool.

The four stages of the coin-bending process are described in Figure 1. The initial stage is freebending (Figure 1a). In the second stage, the ends of the workpiece continue to slide and are touching the die walls (Figure 1b). Then, in the third stage, the ends of the workpiece are lifted and are touching the punch walls (Figure 1c). Lastly, the bending process is completed when all workpiece surfaces are touching the punch and the die in the bottoming stage (Figure 1d).

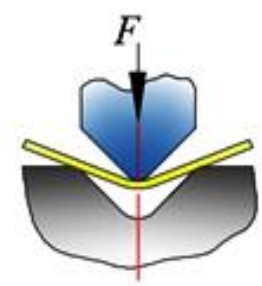

(a)

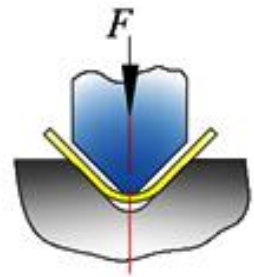

(b)

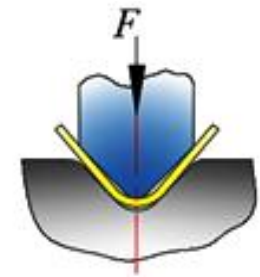

(c)

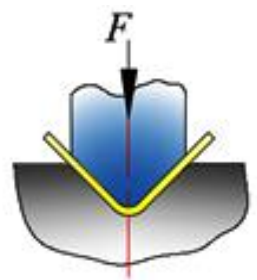

(d)

Figure 1 Coin-bending in V-profile (modified from Boljanovic, 2004)

Thus, free-bending is a part of coin-bending. The profile of punch force in micro V-bending is described in Figure 2.

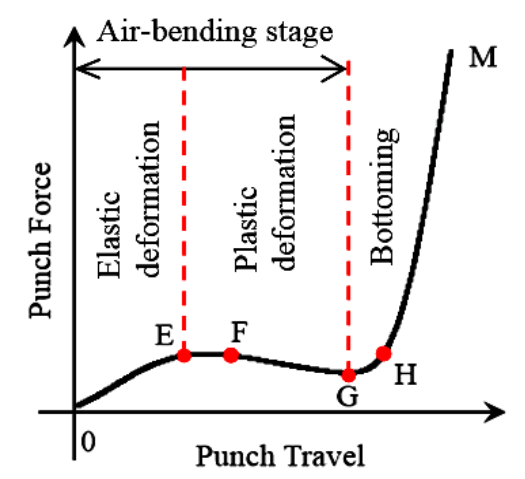

Figure 2 Punch force curve for coin-bending process (modified from Boljanovic, 2004) 
The interval $\mathrm{OG}$ is the free-bending force profile. It has three sub-intervals, namely, the interval $\mathrm{OE}$, as an elastic deformation; the interval $\mathrm{EF}$, where the force is mostly constant; and the interval FG, where the force decreases because the material is being slipped. After that, the force increases to a definitive point. The workpiece will be bent in the interval GH. If the workpiece has to be bottomed, the force will be very quickly increased (interval HM). Chen and Jiang (2011) defined the intervals OE and EG as representing the force profiles for the elastic and plastic deformation, respectively. And, also claimed that the effective stroke is taken when the material going to be bent, i.e., at interval OG.

The force for free-bending in the V-bending process is given by the formula (Boljanovic, 2004):

$$
F=\frac{4 M}{l_{k}-2\left(R_{k}+R_{t}+t\right) \sin \frac{\varphi}{2}} \cos ^{2} \frac{\varphi}{2}
$$

where $M$ is the bending moment for a rectangular cross-section in the purely plastic domain. The simplified formula is (Boljanovic, 2004):

$$
M=n(U T S) \frac{b t^{2}}{4}
$$

where $n$ is the hardening correction coefficient ( $\mathrm{n}=1.6$ to 1.8 ), UTS is the ultimate tensile strength, $b$ is the beam width (bending length), $t$ is the thickness of sheet material, $l_{k}$ is the die opening, and $\varphi$ is the bend angle.

\section{METHODS}

The micro V-bending experiment was conducted using a mounted V-bending tool on a microforming machine with a capacity of $5 \mathrm{kN}$. The experimental setup is described in Figure 3 . The micro-blanking process was conducted to produce a blanked-part as the specimen for the bending process. The dimension of the specimen was $0.1 \times 1.0 \times 7.4 \mathrm{~mm}$. The bending force measurement was performed with a load cell DBCR-50N-002-000 and an NI 9237 4-Ch.

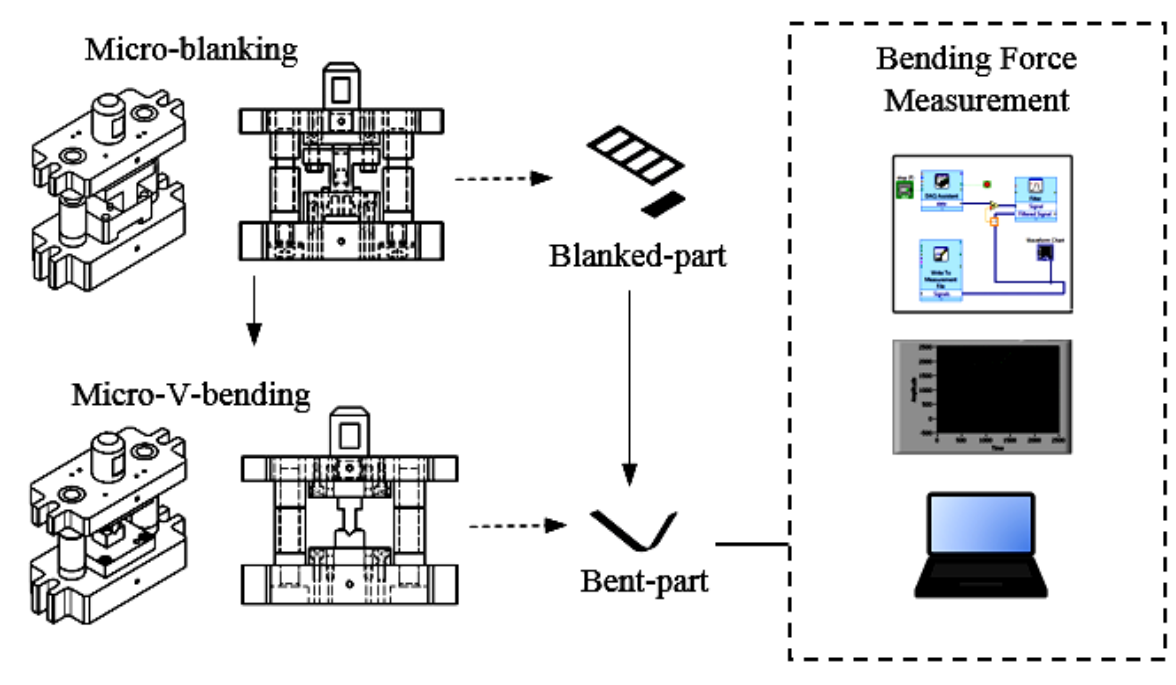

Figure 3 Experimental setup of micro V-bending process 
The micro V-bending tool was fabricated with certain V-shaped dimensions of the punch and die (Figure 4). A partial caging system was used to locate the specimen to be bent since onepiece loading was implemented in the bending process.

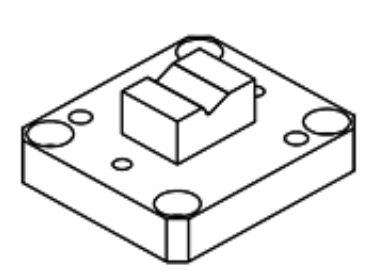

(a)

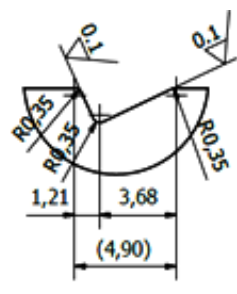

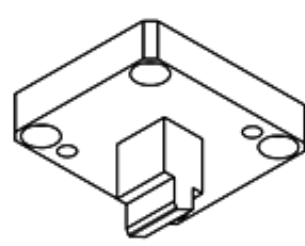

Figure 4 Micro V-bending: (a) die; and (b) punch

The minimum requirements of the material properties for the punch, die and locator was fulfilled by tool steel material, while machinery steel was appropriate for the others. AISI D2 was selected for the former, while AISI 1045 was selected for the latter. The mechanical properties of both types of steel can be seen in Table 1 .

Table 1 Mechanical properties of AISI D2 and AISI 1045

\begin{tabular}{lccc}
\hline \multicolumn{1}{c}{ Properties } & Unit & (AISI D2) & (AISI 1045) \\
\hline Ultimate tensile & {$[\mathrm{MPa}]$} & & 569 \\
strength & {$[\mathrm{MPa}]$} & 1650 & 343 \\
Yield Strength & {$[\%]$} & & 20 \\
Elongation & {$[\mathrm{GPa}]$} & 209.9 & 205 \\
Modulus of Elasticity & & & 0.29 \\
Poissons Ratio & {$[\%]$} & & 55 \\
Machinability & {$[\mathrm{GPa}]$} & & 80 \\
Shear Modulus & & \\
\hline
\end{tabular}

The micro-forming machine was driven by the NX940MS-PS10-3 servo motor. The ball screw and ram configuration transferred the mechanical force and transformed the rotational motion into a translational one (Kiswanto et al., 2013). The micro-forming machine construction is shown in Figure 5.
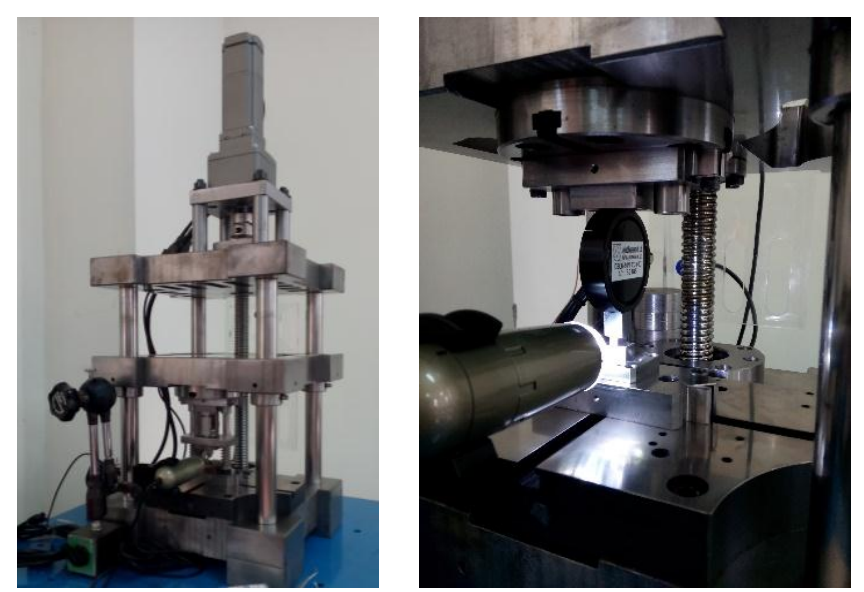

Figure 5 Micro-forming machine 
The micro V-bending investigation used copper foil with a thickness of $0.1 \mathrm{~mm}$. The Optical Emission Spectrometer was used to obtain the chemical composition of the foil (Table 2), and the tensile test was carried out on the Servopulser Shimadzu 20T to determine its mechanical properties (Table 3). No pre-heated process was applied to the material foil since the experiment observed the process with the given properties.

Table 2 Chemical composition of the copper foil

\begin{tabular}{cccccccc}
\hline $\mathrm{Cu}(\%)$ & $\mathrm{Zn}(\%)$ & $\mathrm{Pb}(\%)$ & $\mathrm{Sn}(\%)$ & $\mathrm{P}(\%)$ & $\mathrm{Mn}(\%)$ & $\mathrm{Fe}(\%)$ & $\mathrm{Ni}(\%)$ \\
\hline 98.5 & 0.191 & 0.024 & 0.046 & 0.195 & 0.003 & $<0.005$ & 0.111 \\
\hline \hline $\mathrm{Si}(\%)$ & $\mathrm{Mg}(\%)$ & $\mathrm{Cr}(\%)$ & $\mathrm{Al}(\%)$ & $\mathrm{Ag}(\%)$ & $\mathrm{Co}(\%)$ & $\mathrm{Bi}(\%)$ & $\mathrm{Sb}(\%)$ \\
\hline 0.042 & 0.001 & 0.003 & 0.009 & 0.006 & 0.044 & 0.213 & 0.027 \\
\hline
\end{tabular}

Table 3 Mechanical properties of the copper foil

\begin{tabular}{lcc}
\hline Properties & Unit & Value \\
\hline Tensile Strength & {$[\mathrm{MPa}]$} & 647 \\
Yield Strength & {$[\mathrm{MPa}]$} & - \\
Elongation & {$[\%]$} & 1.9 \\
\hline
\end{tabular}

Furthermore, the blanked-part was bent using the micro V-bending tool to obtain a determined bending angle. No lubricant was used during the process. The experiment was performed with five specimens for each punch speed variation: $0.5 \mathrm{~mm} / \mathrm{s}, 1.0 \mathrm{~mm} / \mathrm{s}, 5.0 \mathrm{~mm} / \mathrm{s}$, and $10.0 \mathrm{~mm} / \mathrm{s}$. To ensure the bending force measurement, 1-second holding time was applied in the bottoming position.

\section{RESULTS AND DISCUSSION}

From the experiment results, it can be seen that the punch force profiles in micro V-bending are in line with the force curve in Figure 2. For example, the punch force profile for punch speed $v_{1}$ $(0.5 \mathrm{~mm} / \mathrm{s})$ is shown in Figure 6. The curve shows a complete punch traveling from the exact contact position to the punch origin position.

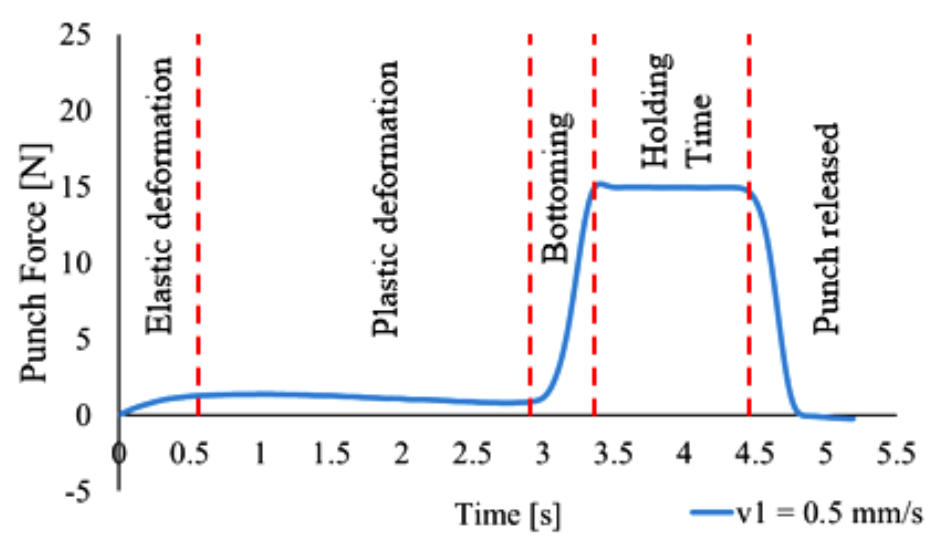

Figure 6 Punch force profile with punch speed $v_{1}$ 
In Figure 7, it can be seen that different punch speeds will affect the punch force at the bottoming stage. The higher the punch speed, the greater the bottoming force. The bottoming stage was held for a short time, but the increase of the force was very impressive. In the initial part of the bottoming stage, the punch was held very close to the bottoming position. Based on the accelerated motion calculation, it was found that acceleration occurred approximately in $10 \%$ of the total punch trajectory length, before the end of the bottoming position,

The free-bending curves were also in line with the curve in Figure 2. The timing of the freebending stages depends on the punch speed. However, the force magnitudes in this stage are the same for all punch speeds, and can be obtained from Equations 1 and 2. According to those equations, the punch speed did not affect the magnitude of the force.

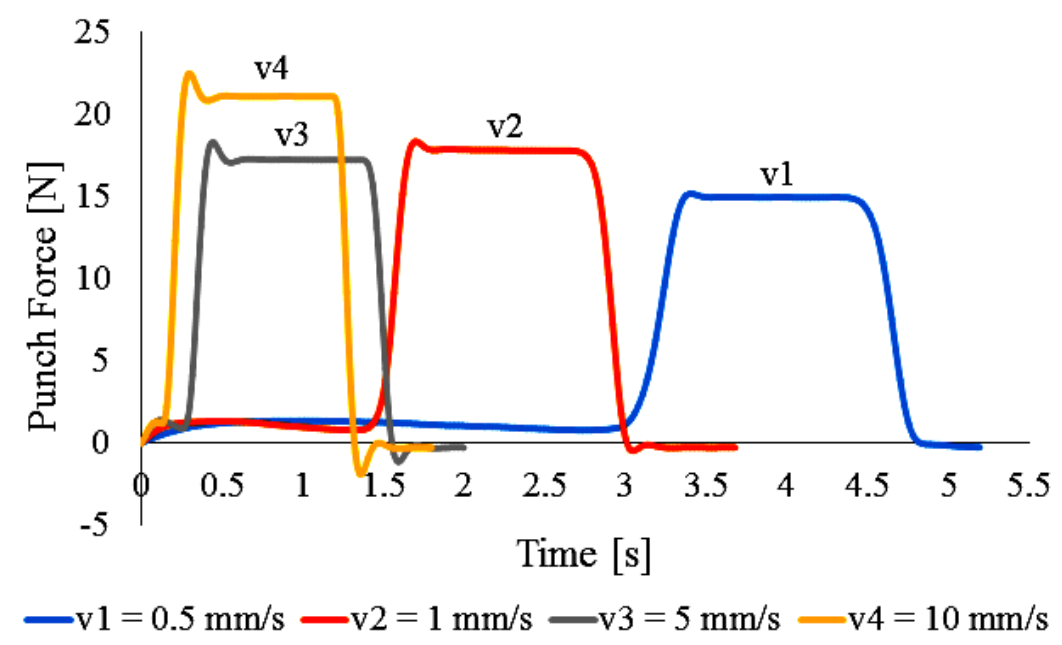

Figure 7 Bottoming force profile with various punch speeds

The average bottoming punch force is described in Figure 8. The trend line shows that the bottoming force increases with increasing punch speed; this is due to the inertia effects of the punch.

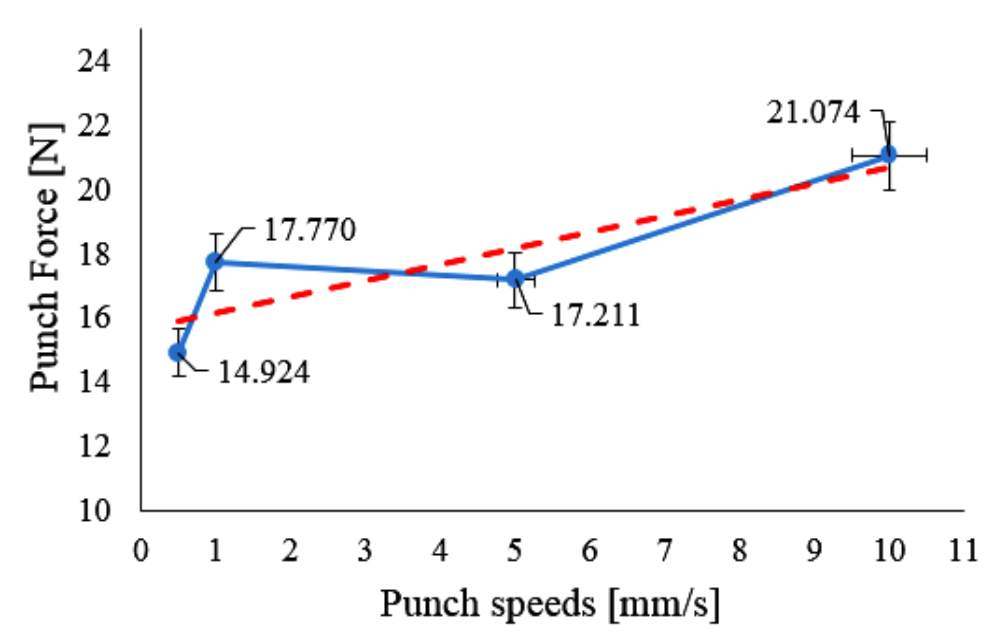

Figure 8 Bottoming force average with various punch speeds 


\section{CONCLUSION}

The results showed that the punch force profile in the micro V-bending process consists of the free-bending force and the bottoming force. Based on the formula of the free-bending force, the factors that can influence the force are the mechanical properties and geometry of the material to be bent. From the experimental results, it was proven that the punch speed did not affect the magnitude of the free-bending force at this stage.

The initiation of the bottoming process occurred very close to the end of the free-bending stage. The force increased significantly after the bending force was obtained at a certain point. At this stage, the force magnitude was clearly affected by the punch speed. The bottoming force increased with increasing punch speed due to the inertia effects of the punch.

For further works, more investigation is required to observe the influence of the punch force on the occurrence of spring back in the bent-part.

\section{REFERENCES}

Boljanovic, V., 2004. Sheet Metal Forming Process and Die Design, 200 Madison Avenue New York, New York 10016, Industrial Press Inc.

Chen, C.-C., Jiang, C.-P., 2011. Grain Size Effect in the Micro-V-bending Process of Thin Metal Sheets. Materials and Manufacturing Processes, Volume 26, pp. 78-83

Gong, F., Guo, B., Wang, C., Shan, D., 2011. Micro Deep Drawing of Micro Cups by using DLC Film Coated Blank Holders and Dies. Diamond and Related Materials, Volume 20(2), pp. 196-200

Hu, Z., Schubnov, A., Vollertsen, F., 2012. Tribological Behaviour of DLC-films and their Application in Micro Deep Drawing. Journal of Materials Processing Technology, Volume 212(3), pp. 647-652

Kiswanto, G., Mahmudah, A., Priadi, D., 2017. Preliminary Investigation of Micro-V-Bending. MATEC Web Conf., Volume 108, 06001

Kiswanto, G., Mahmudah, A., Supriadi, S., 2013. Development and Testing of $5 \mathrm{kN}$ Micro Forming Machine for Micro Part Manufacturing. In: Proceedings of the $13^{\text {th }}$ Quality in Research, 2013 Yogyakarta, Indonesia

Qin, Y., 2010. Micromanufacturing_Engineering_and_Technology, William Andrew

Vollertsen, F., Hu, Z., Niehoff, H.S., Theiler, C., 2004. State of the Art in Micro Forming and Investigations into Micro Deep Drawing. Journal of Materials Processing Technology, Volume 151(1-3), pp. 70-79

Zheng, W., Wang, G., Zhao, G., Wei, D., Jiang, Z., 2013. Modeling and Analysis of Dry Friction in Micro-forming of Metals. Tribology International, Volume 57, pp. 202-209 